\title{
ANÁLISE QUANTITATIVA DE CORPOS DE NEURÔNIOS EM CÓRTEX CEREBRAL DE CAMUNDONGOS TRATADOS COM SYZYGIUM CUMINI
}

Luiz Fernando de Matos XAVIER ${ }^{1}$

Priscila Veloso da SILVA

Raquel Mezzalira RUANO ${ }^{3}$

Deila Rosély CARNEIRO ${ }^{4}$

Andréa Mollica do Amarante PAFFARO ${ }^{5}$

Alessandra ESTEVES 6

1. Acadêmico do curso de Enfermagem da Escola de Enfermagem da Universidade Federal de Alfenas (EEUNIFALMG) e Bolsista Capes programa Ciência sem Fronteiras no Institute of Technology Tralee, Irlanda, email:If_xavier@hotmail.com

2. Biomédica graduada pela Universidade Federal de Alfenas (UNIFAL-MG) e-mail: prizinhahvs@hotmail.com

3. Biomédica graduada pela Universidade Federal de Alfenas (UNIFAL-MG) e-mail: quelruano@ hotmail.com

4. Docente no Instituto de Ciências Biomédicas da Universidade Federal de Alfenas (UNIFAL-MG); Doutora em Fisiopatologia da Reprodução e Inseminação Artificial pela Universidade Federal de Santa Maria (UFSM) e-mail: deila.carneiro@unifal-mg.edu.br

5. Docente do Instituo de Ciências Biomédicas da Universidade Federal de Alfenas (UNIFAL-MG); Pós Doutora pelo Departamento de Biologia Celular e do Desenvolvimento- Instituto de Ciências Biomédicas da Universidade de São Paulo (USP) e-mail: andrea.paffaro@unifal-mg.edu.br

6. Docente no Instituto de Ciências Biomédicas da Universidade Federal de Alfenas (UNIFAL-MG); Doutora em Ciências Morfofuncionais pela Universidade de São Paulo (USP) e-mail: alessandra.esteves@unifal-mg.edu.br

Recebido em: 30/05/2014 - Aprovado em: 15/09/2014 - Disponibilizado em: 15/12/2014

RESUMO: O Syzygium cumini, planta conhecida popularmente como “Jambolão", “Jamelão" ou ainda "Jalão", é uma árvore pertencente à família Myrtaceae encontrada principalmente nos continentes americano e asiático. Amplamente utilizada na medicina alternativa, o Syzygium cumini é conhecido e empregado popularmente no tratamento e ou alívio de sintomas do diabetes mellitus (DM), desordens gastrointestinais, leucorréia, dermopatia, hipertermia entre outros; há também evidências de efeitos no sistema nervoso central (SNC) e propriedades anti-inflamatórias, antifúngicas e antibacterianas. O objetivo foi analisar quantitativamente possíveis efeitos adversos do Syzygium cumini sobre o córtex cerebral de camundongos Swiss. Utilizou-se 16 camundongos Swiss, fêmeas, em idade adulta, peso variando entre 35 e 50 gramas e provenientes do biotério central da Universidade Federal de Alfenas (UNIFAL-MG). Os animais foram divididos em dois grupos denominados: Grupo Controle (GC) e Grupo Tratado (GT). Foi preparada infusão utilizando folhas do Syzygium cumini e administrada nos animais do grupo tratado por meio de uma sonda oroesofágica (gavagem) durante 28 dias. Os animais foram submetidos à eutanásia no $31^{\circ}$ dia tiveram amostras do encéfalo coletadas, fixadas e processadas. As lâminas histológicas obtidas foram analisadas e contabilizou-se o número de corpos celulares de neurônios encontrados em seis campos distintos do córtex cerebral de cada camundongo. Os dados obtidos foram registrados e analisadas usando-se o teste de Mann - Withney. Não foram observadas alterações histológicas, entretanto a análise estatística apontou alterações quantitativas entre o número de neurônios de GC e CT indicando influência da planta sob o SNC.

Palavras chave: Syzygium cumini. Jambolão. Fitoterapia. Sistema Nervoso Central.

\section{QUANTITATIVE ANALYSIS OF BODIES IN CEREBRAL CORTEX NEURONS OF MICE TREATED WITH SYZYGIUM CUMINI}

\begin{abstract}
Syzygium cumini plant popularly known as "Jambolão", "Jamelão" or "Jalam", is a tree belonging to the family Myrtaceae found mainly in the American and Asian continents. It is widely used in alternative medicine and popularly known and used in the treatment or alleviation of symptoms of diabetes mellitus ( DM ), gastrointestinal disorders, leucorrhoea, dermopathy, hyperthermia among others. There is also evidence of central nervous system (CNS) and anti-inflammatory, antifungal and antibacterial properties. The objective was to quantitatively analyze
\end{abstract}


possible adverse effects of Syzygium cumini in the cerebral cortex of Swiss mice. We used 16 Swiss mice, females in adulthood, weighing between 35 and 50 grams and from the animal colony of the Federal University of Alfenas ( UNIFAL - MG ). The animals were divided into two groups called the Control Group (GC) and Treaty Group (GT). It was prepared an infusion using leaves of Syzygium cumini and administered to the treated group oroesofágica through a tube ( gavage ) lasts 28 days. The animals were sacrificed and brain samples was collected, fixed and processed . The histologic slides obtained were analyzed and counted the number of cell bodies of neurons found in six distinct areas of the cerebral cortex of each animal. The data were recorded and analyzed using the Mann - Whitney test. No histological changes were observed, but the statistical analysis showed quantitative changes between the number of neurons of GC and CT indicate the influence of the plant under the CNS.

Keywords: Syzygium cumini. Jambolão. Phytotherapy. Central nervous system.

\section{INTRODUÇÃO}

O Syzygium cumini, planta
conhecida popularmente como
"Jambolão", "Jamelão" ou ainda "Jalão",
é uma árvore pertencente à família
Myrtaceae encontrada principalmente nos
continentes americano e asiático. Nativa da
Índia, seus frutos são comestíveis
possuindo sabor adstringente e apresentam
coloração roxa quando maduros. A planta
possui em seus constituintes os
flavonoides, as saponinas, os ácidos graxos, o tanino, o eugenol, a antimielina e os triterpenos os quais são responsáveis pelas principais características bioquímicas do vegetal (SIANI, 2000).

Amplamente utilizada na medicina alternativa, o Syzygium cumini é conhecido e empregado popularmente no tratamento do diabetes mellitus (DM), em especial nos pacientes insulinodependentes. Somado há isso, há evidências de propriedades antiinflamatórias segundo estudo realizado por Muruganandan et al. (2001), além do Syzygium cumini ser utilizado como forma de tratamento de desordens gastrointestinais, apesar do potencial efeito irritante à mucosa destas regiões anatômicas. Por fim, em estudo realizado por Chandrasekaran (2004) houve evidência de atividade antifúngica e antibacteriana da planta; suas folhas também são empregadas no fortalecimento de dentes e gengivas, no tratamento de leucorréia, hipertermia, estrangúria, dermopatia, constipação e inibição da liberação de sangue no conteúdo fecal. (WARRIER et al., 1996 apud ABD ELMONEIM, 2011)

O Syzygium cumini apresenta ainda efeitos no sistema nervoso central (SNC) dentre os quais se ressalta propriedades anticonvulsivantes, sedativas e depressoras (DE LIMA et al., 1998; CHAKRABORTY et al., 1986) assim como alterações do efeito inibitório na atividade da acetilcolinesterase no cerebelo e no córtex cerebral e um aumento na atividade dessa enzima no estriato. (SCHOSSLER, et al., 2005).

A fitoterapia e outras práticas farmacológicas tradicionais são amplamente utilizadas pela população mundial, entretanto nestas modalidades 
terapêuticas nem sempre uma apropriada avaliação da relação risco-benefício é realizada (Brasil, 2008). No Brasil, o emprego desta modalidade terapêutica é realizado por meio de restritos, ou até mesmo inexistente, conhecimentos científicos acerca das propriedades farmacológicas inerentes ao fitoterápico. As informações referentes a estes medicamentos geralmente são propagadas por usuários ou comerciantes podendo, inclusive, serem empregados para fins medicinais diferentes daqueles utilizados pelos silvícolas (VEIGA JÚNIOR; PINTO; MACIEL, 2005).

A utilização de plantas medicinais não é isenta de efeitos colaterais, interações medicamentosas ou contraindicações. Elas apresentam substâncias que podem ser tóxicas, desencadeando reações adversas. Além disso, a utilização da dose incorreta, do componente da planta indevido ou ainda a automedicação errônea podem causar efeitos colaterais indesejáveis (TUROLLA; NASCIMENTO, 2006).

Assim, tendo em vista as propriedades atribuídas ao Syzygium cumini, à ampla utilização do mesmo como fitoterápico no Brasil e a escassez de estudos no que diz respeito à viabilidade $\mathrm{e}$ segurança na utilização da planta, idealizou-se a presente investigação cujo objetivo é analisar quantitativamente possíveis efeitos adversos do Syzygium cumini sobre o córtex cerebral de camundongos Swiss.

\section{MATERIAL E MÉTODO}

O presente estudo foi desenvolvido utilizando-se 16 camundongos Swiss, fêmeas, em idade adulta, peso variando entre 35 e 50 gramas e provenientes do biotério central da Universidade Federal de Alfenas (UNIFAL-MG). Os animais permaneceram em regime ad libidum sendo ofertada dieta sólida e líquida durante todo o experimento. As folhas provenientes do Syzygium cumini foram coletadas no município de Alfenas (Minas Gerais) em acordo com os parâmetros exigidos pelo Instituto Brasileiro de Ampara ao Meio Ambiente. Previamente ao início do experimento a planta foi devidamente identificada e registrada no herbário da Universidade Federal de Alfenas (UNIFAL-MG).

O material vegetal (folhas) obtido da planta foi seco em estufa a $37^{\circ} \mathrm{C}$ durante 72 horas, posteriormente trituradas e imersas em água destilada há $80{ }^{\circ} \mathrm{C}$ na proporção de 20 gramas de folha para cada $1000 \mathrm{ml}$ de água. Após infusão, a solução permaneceu inerte até atingir temperatura ambiente sendo então filtrada e, posteriormente, administrada nos animais. 
Os animais foram divididos em dois grupos denominados: Grupo Controle (GC) e Grupo Tratado (GT) cada qual com 8 camundongos. A solução preparada com folhas do Syzygium cumini foi administrada nos animais do grupo tratado por meio de uma sonda oroesofágica (gavagem) durante 28 dias em uma dose diária de $0,528 \mu \mathrm{L}$ e $0,520 \mu \mathrm{L}$ sucessivamente . A dose administrada foi calculada a partir da média dos pesos e adequada à proporção que assemelha à consumida por um indivíduo de $70 \mathrm{~kg}$ em um dia (aproximadamente 1L de chá/dia). Os animais pertencentes ao Grupo Controle permaneceram em regime ad libidum e não foram submetidos a uma dose diária de água por gavagem devido a constatação de que na frequência diária única, o procedimento não resulta em estresse para os camundongos.

Os animais foram submetidos à eutanásia no $31^{\circ}$ dia após início do tratamento e tiveram o encéfalo coletado, seccionado de maneira a separar os hemisférios cerebrais e, após separação, o material foi fixado. $\mathrm{O}$ processamento das amostras iniciou-se realizando por meio da lavagem em água corrente durante 30 minutos e mantidos em álcool 70\% overnight. Após 12 horas, o material foi desidratado por uma bateria crescente de etanol (95\%, Absoluto I e II) e diafanizados em duas imersões consecutivos de Xilol. Ao término da desidratação e diafanização, as amostras foram embebidas em parafina contendo DMSO (Histosec - Merck Chemical Co, SP, BR) diluída 1:1 com xilol por um período de 1 hora em estufa aquecida a $60^{\circ} \mathrm{C}$, após foram realizadas outras duas embebições em parafina pura durante 1 hora cada em estufa novamente aquecida à $60^{\circ} \mathrm{C}$. O material foi então incluído em parafina pura mantida à temperatura ambiente por 24 horas. Cortes de $7 \mu \mathrm{m}$ de espessura foram obtidos em um micrótomo rotativo (Leica RM 2135) e coletados em lâminas histológicas. Procedeu-se com a desparafinização em xilol e hidratação destes cortes histológicos; as lâminas foram submetidas a técnicas de coloração de violeta cresil com vistas a viabilizar o estudo das células neuronais.

As lâminas histológicas foram observadas em microscópio óptico (Nikon) acoplado ao sistema de captura de imagem Digital Sight DSFil e descritas detalhadamente baseadas nas análises comparativas com o grupo controle. A análise quantitativa foi realizada a partir do software NIS element (Nikon) acoplado ao sistema de captura de imagem descrito no item anterior. Os cortes seriados dos hemisférios cerebrais coletados foram 
analisados através de parâmetros quantitativos.

Foram contabilizados os corpos celulares de neurônios encontrados em seis campos distintos do córtex cerebral sendo

três de cada hemisfério (direito e esquerdo) de oito fêmeas tratadas e oito fêmeas pertencentes ao grupo controle. Os dados obtidos foram registrados e expressos como mediana (por serem não paramétricos). Diferenças entre o grupo controle e os tratados foram analisadas usando-se o teste de Mann - Withney. A análise estatística foi realizado utilizandose o software IBM SPSS Statistcs Version 22.

Tabela I - Teste de Mann-Whitney (estatística do teste)

\begin{tabular}{|l|r|}
\hline & Neurônios \\
\hline U de Mann-Whitney & 1919,000 \\
Wilcoxon W & 6575,000 \\
Z & $-6,985$ \\
Significância Sig. (2 &, 000 \\
extremidades) & \\
\hline
\end{tabular}

Fonte: próprio autor

Tabela II - Teste de Mann-Whitney (classificações)

\begin{tabular}{|cl|r|r|r|}
\hline & Grupos & $\mathrm{N}$ & $\begin{array}{c}\text { Postos de } \\
\text { média }\end{array}$ & $\begin{array}{c}\text { Soma de } \\
\text { Classificaçōe } \\
\text { s }\end{array}$ \\
\hline Neurônios & 1,00 & 96 & 124,51 & 11953,00 \\
& 2,00 & 96 & 68,49 & 6575,00 \\
& Total & 192 & & \\
\hline
\end{tabular}

Fonte: próprio autor

\section{RESULTADOS E DISCUSSÃO}

A análise macroscópica do tecido cerebral evidenciou consistência característica em todas as amostras analisadas. Ao exame microscópico foram observados corpos neuronais piramidais e fusiformes, seguido de pequenos núcleos de células gliais e estruturas fibrosas curtas dendríticas e axonais. Não houve evidência de moléstia neuronal como picnose e apoptose o que esta em acordo com Schossler et al.(2005).

A análise estatística realizada evidenciou que o número de neurônios no córtex cerebral apresentados pelos animais pertencentes ao grupo controle é superior àquele encontrado nos animais tratados com a infusão das folhas do Syzygium cumini e as diferenças observadas foram estatisticamente significativas (Tabelas I e II). 
Durante a realização do experimento observou-se alteração do comportamento típico dos animais pertencentes ao grupo tratado. Os camundongos apresentaram-se estressados após o inicio da administração da infusão preparada.

A Organização Mundial da Saúde (OMS) atenta para a necessidade de executar ações para o devido controle de qualidade dos produtos fitoterápicos. Problemas relacionados à má procedência do produto, erros na identificação botânica, acondicionamento inadequado, dose estão rotineiramente associados ao uso de plantas medicinais. Por fim, a crença popular equivocada na qual "tratamento com plantas naturais não fazem mal" consiste em um grande revés no que diz respeito a esta modalidade terapêutica (MENON-MIYAKE et al., 2004).

No Brasil, em especial na região sul do país, o chá do Syzygium cumini, está fortemente associado a efeitos hipoglicemiantes sendo amplamente utilizado pela população diabética desta localidade. A auto prescrição e indicação entres portadores do diabetes é realizada de maneira indiscriminada e, na maioria das situações, sem a devida análise do risco versus benefício desta modalidade terapêutica. Conforme citado anteriormente, esta prática está cerceada de riscos que podem resultar em problemas associados à saúde do indivíduo.

O desenvolvimento do estudo utilizando-se de infusão das folhas do Syzygium cumini seguido de uma adaptação da dose diária àquela utilizada popularmente possibilitou aproximar-se à forma utilizada do chá da planta pela população. Neste sentido, chama-nos atenção a existência de diferenças quantitativas significantes entre as amostras sendo a contagem neuronal inferior em camundongos pertencentes ao grupo tratado com infusão, algo que aponta para questionamentos acerca do risco/benefício do uso desse fitoterápico por parte da população.

Sugerem-se novas investigações acerca das propriedades fitoterápicas e segurança na utilização do Syzygium cumini como fitoterápico uma vez que a OMS alerta para a necessidade dessas modalidades de estudos e tendo em vista os resultados obtidos. Associado a isto, estudos com ênfase ao caráter patológico da planta em especial no sistema nervoso central e periférico, rins e fígado são sugeridos a fim de aprofundar os efeitos do Syzygium cumini no organismo. 


\section{CONCLUSÃO}

Diante dos resultados obtidos, conclui-se que a infusão obtida a partir do Syzygium cumini não produz alterações macroscópicas no encéfalo de camundongos Wistar. Entretanto, devido à análise estatística realizadas houve

\section{REFERÊCIAS}

ABD EL-MONEIM M. R. A.; SAYED A. F.; EMAD A. S.; HANY A. E. Syzygium cumini (pomposia) active principles exhibit potent anticancer and antioxidant activities. African Journal of Pharmacy and Pharmacology. v. 5, p. 948-956, 2011. DOI: $10.5897 / A J P P 10.420$

\section{CHANDRASEKARAN, M.;}

VENKATESALU, V. Antibacterial and antifungal activity of Syzygium jambolanum seeds. Journal of Ethnopharmacology, v.91, p. 105-108, 2004.

CHAKRABORTY, D., MAHAPATRA, P.K., CHAU-DHURI, A.K.N.A neuropsychopharmacolo-gicalstudy of Syzygium cumini. Planta Médica,Stuttgard, v. 2, p. 130-143, 1986. significativas variações no número de neurônios do córtex cerebral dos animais tratados com a infusão da planta. Em termos histológicos não foram notadas alterações morfológicas teciduais ou qualquer evidência de processo patológico nas amostras realizadas.

DE LIMA, T.M., KLUEGER, P.A., PEREIRA, P.A.,NETO, W.P.M., MORATO, G.S., FARIAS, M.R.Behavioural effects of crude and semi-purifiedextracts of Syzygium cumini linn. Skeels. Phyto-therapy Research, London, v. 12, p. 488-493, 1998.

MENON-MIYAKE, M.A. et al. Inquérito sobre o uso de plantas medicinais para tratamento de afecções otorrinolaringológicas entre pacientes de um hospital público terciário. Rev Bras

Otorrinolaringologia, v. 70, p. 43-55, 2004. Disponível em:

$<$ http://revistas.ucg.br/index.php/estudos/a rticle/view/243/188>. Acesso em: 29 maio 2014.

MURUGANANDAN, S., SRINIVASAN, K., CANDRA,S., TANDAN, S.K., LAL, J., RAVIPRAKASH. Anti-inflammatory 
activity of Syzygium cumini bark.

Fitoterapia, Milano, v. 72, n. 4, p.369-

375, 2001.

SCHOSSLER, D.R.C et al. Avaliação dos efeitos adversos do Syzygium cumini no sistema nervoso central e trato gastrintestinal de ratos normais e diabéticos. Veterinária Notícias, Uberlândia, v. 11, n. 1, p. 19-23, 2005.

SIANI, A.C., SAMPAIO, A. L. F, SOUZA, M. C., HENRIQUES, M.G.M.O, RAMOS, M.F.S. Óleos essenciais, potencial anti-inflamatório, Revista

\section{Biotecnologia Ciência \&}

>. Acesso em: 29 maio 2014.
Desenvolvimento, v.3, n. 16, p.38-43, 2000.

TUROLLA, M. S. R.; NASCIMENTO, E. S. Informações toxicológicas de alguns fitoterápicos utilizados no Brasil. Revista Brasileira de Ciências Farmacêuticas, v. 42, n. 2, 2006.

VEIGA JUNIOR, V. F.; PINTO, A. C.; MACIEL, M. A. M. Plantas medicinais: cura segura? Quím. Nova [online], v. 28, n. 3, p. 519-28, 2005. Disponível em: $<$ http://www.scielo.br/pdf/qn/v28n3/24145. $\underline{p d f}$ 